\title{
Research on the Unique Cultural Characteristics of Shanghai Style Paper Cutting
}

\author{
Fang Wu
}

Shanghai Publishing and Printing College, Shanghai, China.

Keywords: intangible cultural heritage; Shanghai style paper cutting; Shanghai-style culture.

\begin{abstract}
With the marketization of light and handicraft industries in Shanghai, Shanghai style paper-cut has bordered on the extinction. In 2007, the "Shanghai style paper cutting" was officially included in the municipal intangible cultural heritage list; in 2008, it was included in the national intangible cultural heritage supplement list. In 2009, together with the other thirteen provinces and cities of China, Shanghai style paper cutting was included in the world intangible cultural heritage list by UNESCO by the name of "Chinese paper-cut". Under the background of protecting and developing the intangible cultural heritage, this paper introduces the unique characteristics of Shanghai style paper cutting from two aspects: the influence of Shanghai style culture and the uniqueness of Shanghai style paper cutting, and emphasizes that Shanghai style paper cutting has special protection value and development significance in the inheritance process.
\end{abstract}

\section{Introduction}

In the article Urban Culture and Modernity, Ou-fan Li described Shanghai as a "metropolis", which required "a world of itself". Because of the concession (foreign settlement) history, Shanghai was the only international metropolis in China at that time. In addition to high buildings in concessions, the old city of Shanghai could also be found in the Town God's Temple area. Therefore, Shanghai has been the "Tale of Two Cities" from the beginning. Concessions coexist with the old city, one representing foreign culture, the other representing popular culture in the south of China. [1] In fact, if we identify cultural forms in Shanghai from building styles, the number was much greater than "two". Roughly calculated, there were about 6 kinds of representative buildings in Shanghai in the last century: World Architecture in the Bund, shop streets, foreign houses in French concession, the Confucian Temple in Yu Garden, Shikumen, as well as new residential quarters for workers built after 1949. Different building styles represent different living cultures and habits; behind these architectural forms is the entire history of Shanghai. Before 1949, the corresponding relationship between urban buildings and residential culture in Shanghai is shown in Table 1. According to different residential areas, 6 kinds of residential environment could be found. The architectural environment not only reflects people's daily life, but also reflects a wide variety of social facts, including characteristics of natural environment and resources, industrial art, empiricism tradition, application of experimental knowledge, social organization and cooperation process, as well as the believes and values of the whole society. [2] The pluralism and complexity of urban architectural culture in Shanghai originates from its unique historical and cultural environment. Architectural form is a specific and clear existence. Through the long period of daily life, the belief of urban citizens becomes specific and explicit. Shanghai culture is gradually formed because of the continuation of time and the accumulation of culture.

As Spengler said, the "appearance" of a city was a part of its history; it reflects the spiritual history and culture of the city. [4] Shanghai's long changing and wonderful urban appearances undoubtedly play a decisive role in the inheritance and development of Shanghai style paper cutting.

Due to the developed industry and commerce, people from all walks of life and various industries came to Shanghai from different parts of China. Diversified kinds of folk arts and cultures exchange and develop in Shanghai, improving the economic development level of this region, opening up the market space and offering conditions to the inheritance of urban folklore. The two representative 
founders of Shanghai style paper cutting, Zi-gan Wang and Xi-ming Lin lived and grew up in Shanghai. They were familiar with cultures in Shanghai, and naturally integrated the spirit of this city into their artistic creation. The art of Shanghai paper-cut has unique artistic characteristics of all-embracing, absorbing all kinds of talents and consciously following the times. In essence, Shanghai-style culture refuses the comparison between different regions. Thus, Shanghai paper cutting is not trapped into the single local culture with self-centralism. Meanwhile, Shanghai-style culture advocates the integration of Chinese and Western cultures, encourages the commercial culture of marketplace, and seeks for the coexistence of multi art forms as well as novelties in cultural features. These cultural characteristics should be compared with the inheritance and protection of Shanghai style paper cutting, in order to analyze and understand Shanghai style paper cutting, and the city of Shanghai as a whole.

Table 1 Corresponding relationship between residences and residential cultures in Shanghai before 1949 [3]

\begin{tabular}{|c|c|}
\hline residences & $\begin{array}{l}\text { residential cultures } \\
\end{array}$ \\
\hline shanty areas in Chinese concession & $\begin{array}{l}\text { culture of workers from the bottom of } \\
\text { society }\end{array}$ \\
\hline Shikumen in foreign concessions & $\begin{array}{l}\text { culture of clerks from the middle layer of } \\
\text { society }\end{array}$ \\
\hline 1 & Gang culture \\
\hline Shikumen in foreign concessions & petty bourgeoisie culture \\
\hline independent villas & $\begin{array}{c}\text { culture of bureaucrats and national } \\
\text { capitalists }\end{array}$ \\
\hline $\begin{array}{c}\text { international settlements } \\
\text { French concessions }\end{array}$ & foreign immigrant culture \\
\hline
\end{tabular}

\section{The Influence of Shanghai-style Culture}

Shanghai-style is the expression of modern Chinese commercial culture. [5] Shanghai-style culture originated from two artistic forms: painting and drama. [6] In the book History of Chinese Painting which was published in 1937, there were records about "Shanghai-style" painting: "during the reign of Tongzhi and Guangxu, the political situation became bad. The art of painting was fading. Most of the painters lived in Shanghai... 'Shanghai-style' was gradually formed." [7] Meanwhile, in the late Qing Dynasty, the circle of Peking Opera took Beijing as the center, and called drama forms from other provinces as "Shanghai-style". So the word referred to areas except Beijing. These two items are the earliest sources of "Shanghai-style". One of them specifically refers to Shanghai, while the other refers to areas except Beijing. Xun Lu proposed a famous theory about Beijing-style and Shanghai-style in Shenbao Newspaper on February 3, 1934. [8] The article summed up the characteristics of "Shanghai-style" as "offshore culture and commerce oriented". In modern times, the inner meaning of Shanghai-style is further expanded. It can not only express the daily life of Shanghai citizens, but also refer to some culture and art forms.

Shanghai-style culture has multiple connotations and two characteristics which greatly influence the folk art of Shanghai, including Shanghai style paper cutting: heterogeneous culture and the changing folklore.

\subsection{Heterogeneous culture.}

The development of culture is always depended on the over-all historical environment. In the course of modern history, two kinds of cultural forms with typical representative meanings come into being in Shanghai: concession culture (European and American Culture) and commercial culture. The two cultures reflect the heterogeneous cultural attribute which is important in the interpretation of Shanghai-style. First of all, the concession culture comes from Europe and America, and is essentially different from the local culture of Shanghai. Secondly, the commercial culture is not in 
line with traditional Chinese concept which advocates study and being officials. Thus, modern Shanghai is different from the traditional Chinese culture. In particular, "Shanghai-style" strives for novelty, emphasizes the importance of commerce and caters to the market, while the traditional Chinese culture follows the beaten track, values agriculture more than commerce, and caters for literati and officialdom. The Shanghai-style culture has distinct features of modern cities, so unavoidably deviates from the traditional Chinese culture. Therefore, comparing to the traditional way of life, the Shanghai-style urban life is actually a spiritual island.

The heterogeneous feature of Shanghai-style culture endows the folk art of Shanghai with corresponding characteristics, which are reflected in the inheritance and development of Shanghai style paper cutting art in the following aspects:

Drawing lessons and merging with other forms of art and different paper cutting styles.

The art of paper cutting is influenced by the market and aesthetic changes of the times.

The theme of paper cutting is not constrained by traditional paper-cut programs, and is good at bringing forth new ideas.

In the list of Chinese paper cutting, the phenomenon of "heterogeneous" paper-cut style brought by immigrant culture also happens in other cities. For example, at first, Gaomi paper-cut in Shandong Province followed the delicate style of eastern Shandong paper-cut. Due to the influence of frequent wars, from Han Dynasty to the first year of Hongwu in Ming Dynasty, a large number of immigrants came to Gaomi from all over the country, brought new characteristics to the art style of paper-cut. Shanghai style paper cutting originated in the area of Jiangsu and Zhejiang, and belonged to the artistic style of southern China. In the past, paper cuttings served as the source of embroidery patterns. The overall features of paper cutting were delicate and beautiful; the themes of creation were traditional festival and auspicious patterns, such as flowers, bird and animals, which catered to the aesthetic needs of Shanghai citizens at that time. With the continuous updating of aesthetic requirements brought by new citizens and the introduction of exotic cultural elements, Shanghai paper-cut is no longer confined to the form and content of embroidery patterns, and becomes a new citizen art form which could express a variety of themes and styles. Although paper-cut artists and inheriting people still respect and follow the rules and concepts of traditional paper cutting, Shanghai style paper cutting is unquestionable representing the characteristics of heterogeneous culture: openness and variable.

The continuous influx of immigrants bring Shanghai with rich and complex cultural elements, as well as lasting powers and rich materials which are required by the development of Shanghai style paper cutting. Shou-bai Li, the representative of Shanghai paper cutting art once said: "Shanghai is an immigrant city; a large number of urban cultures are the replica of immigrant culture." [9] Shanghai is located at the center of cultural transformation; the culture of Shanghai is different from the traditional society. Thus, the theme of creation is also influenced by heterogeneous cultures like business culture and immigration culture.

\subsection{The changing folklore.}

When local citizens' aesthetic habit changes from the traditional culture, the form of paper-cut is bound to change. One possible result is that, the themes and forms of new paper-cut art deviate from the form and style of the traditional one. The alienation from traditional folk culture may bring a "transition dilemma", which is mainly manifested by style disorder, the absence of cause and effect relationship, and the lack of identification and regional characteristics.

In the face of new culture, new trend and new media, traditional folk art has to readjust the "motif" of creation. In essence, it is a rebirth process of deconstruction and construction. Every innovation is an adventure. Both aesthetic tastes and traditional heritage may fall into the trap of "lagging behind", especially when local folklores and fashion trends are changing continuously. In order to be accepted by citizens, the forms of folk arts need to be stable. Once the connections between the "transition dilemma" are too close or even overlapped, their stability will be destroyed. New kinds of folklore do not have enough time to root and sprout; they have to face the impacts of "newer" folklores. The development characteristics of Shanghai style culture are embodied in the art 
of Shanghai paper cutting, which belongs to the latter.

The same situation happens in other thirteen provinces and cities which jointly declared the "Chinese paper-cut" list. Due to the impacts of foreign culture or new cultures, the gap between traditional culture and modern life is becoming obvious, which lead to the temporary shortage of paper-cut artists. But thanks to the changing Shanghai urban culture, Shanghai style paper-cut is used to the replacement and blending of all kinds of foreign cultures. The forms of folk art in an area are dominated by the forms of entertainment in that area. The changing Shanghai urban culture creates citizens' diversified needs and aesthetic tendencies in folklores, cultures and demands. The loss of traditional functions (serve as the embroidery patterns) of Shanghai paper cutting is one of these consequences. As Bausinger said, "we must obey the rules of this time, and accept the fact that the 'aborinigality' in the past is no longer exist." [10] Can we draw the conclusion that the local characters of Shanghai paper cutting are no longer exist? Or, the changing Shanghai-style culture is the cause of declining folk cultures? The fact is just the opposite.

The changes of folklore have impacts on the "aborinigality" of traditional culture. However, the impacts can be weakened, blurred, or established and renewed. In the process of inheritance and development, Shanghai style paper cutting is becoming more and more abundant and inclusive, as it absorb elements in the aesthetics of citizens' daily life, and constantly improve its skills with the development of technology. The changing regional culture can automatically screen out the new culture form which is suitable for the development of the local region and can meet the requirements of local citizens. In fact, the various forms of Shanghai style paper cutting attract more attentions from local people. Therefore, the changing urban culture offers Shanghai style paper cutting with a sense of group identity.

\section{The Uniqueness of the Shanghai Style Paper Cuttings}

\subsection{Inheritance.}

The uniqueness of Shanghai style paper cutting is first reflected in its successor group. The inheritors of Shanghai style paper cutting show the feature of independent development. They create their works and operate their business independently. Even if they belong to the same inheritance vein or in the same inheritance area, they actively practice different creation ideas on paper cutting. For instance, Xiao-qin Xi and Zi-ping Zhao are the students of the same teacher. But after finishing their apprenticeship, they separate and seek for their own paper cutting styles and development paths, and gradually find their unique styles of paper cutting. Xi-ming Lin is one of the founders of Shanghai style paper cutting art; Shou-bai Li is his apprentice. But the style of Li's later works is totally different from his master's. In the art of Shanghai style paper cutting, the apprentice of a master can learn from another teacher. For example, Shou-bai Li learnt from his father Ting-yi Li since childhood, while Ting-yi Li learnt from Zi-gan Wang for a short period of time in his early years. In adulthood, Shou-bai Li learnt from another founder of Shanghai style paper cutting, Xi-ming Lin. The greatest advantage of this kind of inheritance is that, a student can learn the skills and styles of different teachers, and achieve mastery through the comprehensive study. This system can make the heritage of traditional folk art more creative. Another example is Zi-ping Zhao, who learnt from Zi-gan Wang in the early days at the Shanghai Institute of Arts and Crafts, and then learnt from Xi-ming Lin. This way of inheritance provides students with the opportunity of learning widely from different teachers' strong points, then have broader visions as well as richer practical experience.

Compared with other representative provinces and cities, representative inheritors and inheritance areas of Shanghai style paper cutting are not superior in quantity; but a variety of distinctive paper-cut styles can be created in the atmosphere of urban cultural environment. Successors have different creation concepts, but they all represent Shanghai-style paper cutting. This reflects the characteristics of "harmony in diversity" of Shanghai-style spirit.

In terms of the group composition, most of the representative inheritors of Shanghai paper cutting come from art research institutes, educational units and cultural art companies. Among them, painters and senior craft artists take large proportions. They have high culture levels, good aesthetic qualities 
and independent economic situations; they can accept new cultures fast, and have the courage of innovation. Their works are full of modern sense. The professional composition and creative characteristics of Shanghai style paper cutting inheritors reflect the influences of Shanghai-style culture. It is the unique nature of Shanghai the city that nurtures the uniqueness of Shanghai style paper cutting.

\subsection{The theme of the times and the city.}

Both international and local themes can be found in Shanghai-style paper cutting. New urban themes with distinctive characteristics of the times are the most popular and best expressed. As early as 1930 s to 1950s, folk artists in Shanghai began to create paper-cuttings of foreign films which were popular at that time. Paper cuttings appeared on streets and theaters as star pictorials and picture posters. Fashionable girls appeared not only on calendars, but also in paper cutting works with new themes. For example, the image of cheongsam ladies appeared in the modern Shanghai style paper cutting. The production of cheongsam is also a unique intangible cultural heritage of Shanghai, while ladies in cheongsam are in accordance with the concept of the "modern" Shanghai. "The Shanghai style is modern ladies!" [11]
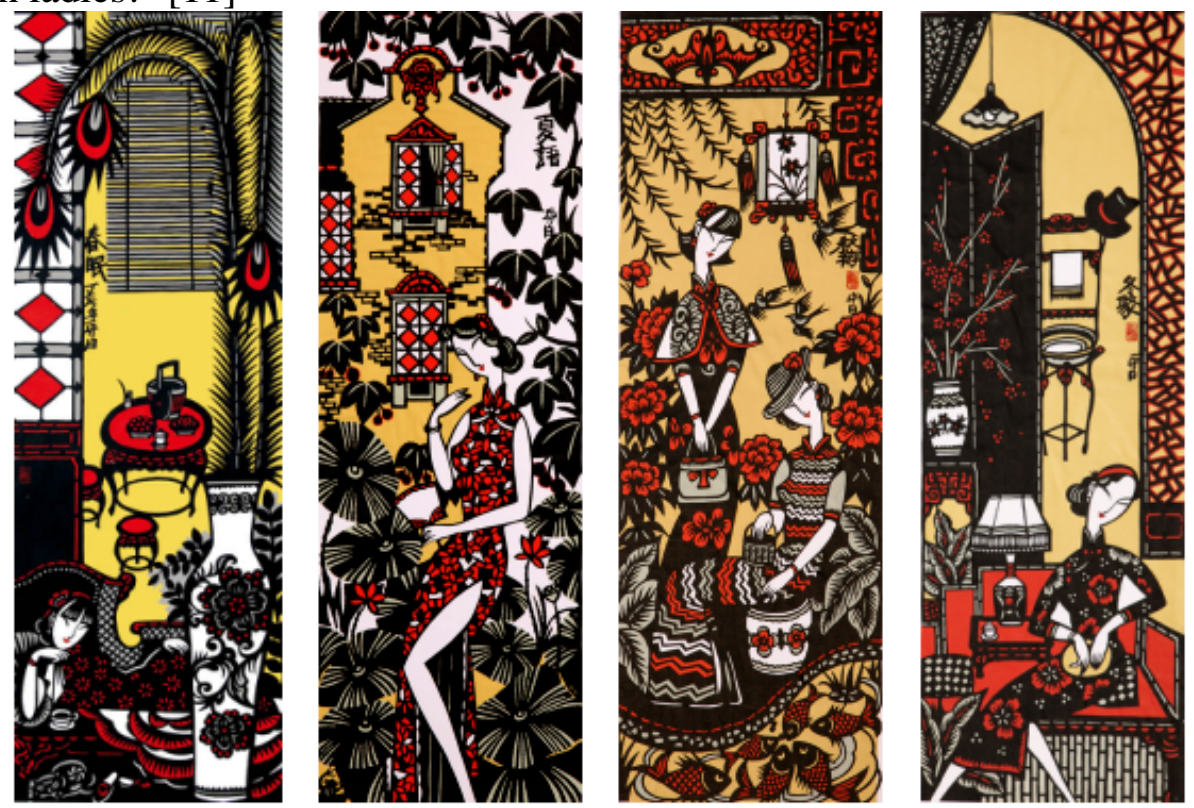

Figure 1. Colorful Shanghai style paper-cut works created by Li Shou-bai in 2007: the series of "spring sleeping", "summer chatting", "autumn touring" and "winter gathering". 900 * 300mm, provided by Shou-bai Li

The New Sensation School rose in 1930s regarded modern ladies as the goddess of urban culture. They believed that modern ladies represented the spirit of rich society and the taste of middle class in commodity aesthetics, foreign fashion trends and popular entertainment. They were hot topics of fashion magazines at that time. Through the form of paper-cut, the image of modern ladies which were popular in the last century is reproduced; the aesthetic concept of the old Shanghai is represented. It is in accordance with the collective nostalgia wave in today's urban culture. This kind of nostalgia combines the memory and imagination of "past years" and the beautiful vision of urban life in the future.

In 1930s, Mo Ran, a writer of New Sensation School, imitated the article of A Psalm of Chinese Women's Beauty written by French modernist writer and journalist Maurice Dekobra, [12] and published The Beauty of Chinese Women in the Eyes of Outsiders. In the essay, Mo provided standard definitions on the beauty of modern women in detail: "She has a pair of almond shaped, slant eyes; a pair of pale red, shell shaped ears, a 'Tiger' mouth, a hawklike nose, a 'tablespoon' chin, a 'half-moon-shaped' forehead, a oval face; her shoulders, thighs and legs are slightly plump and curved; her height is five feet and two inches. Her beauty is mysterious and charming." [13] These descriptions are almost identical with the image of Shanghai woman in Shanghai style paper-cut in 
Figure 1. The emotional appeal and aesthetic identity of Shanghai-style culture are shared by all Shanghai citizens.

\subsection{The expression of native language culture.}

Characters are added in Shanghai-style paper cutting. Sometimes, English letters appear with Chinese characters simultaneously, emphasizing the modern communication function and advertising consciousness of Shanghai-style culture. In particular, the direct application of Shanghai dialect reflects the close relationship between Shanghai paper cutting inheritors and the mother tongue culture, which is another typical manifestation of the unique Shanghai-style culture.

In modern times, immigrants came to Shanghai in batches. Thus, the cultures, languages and customs of immigrants are stored and assimilated by the urban culture. The loss of a language is actually the loss of a culture. It is very necessary to introduce linguistic methods into the study of folk culture. Dialects can accurately convey information and truly reflects the historical heritage and primary ecology of regional cultures. [14] For example, the Manchu folk paper-cut in Changbai Mountain area of Liaoning province displays the decorative Manchu characters in paper-cut works, which greatly increases regional colors and local characteristics. [15] Different from the square writing for outsiders, the application of folk local language is to expound local culture in writing. [16] Paul Celan, a poet from Romania once said: "only through native language can a person speak his truth."

Mother tongue, local folk arts, paper-cut graphics and Shanghai dialect characters construct the new meaning of Shanghai style paper cutting in the urban nostalgic complex. How to display large scale folk paper cutting works through the composition of scattered spots? How to design on the combination of Chinese characters and the black-and-white hollowing effects of paper cuts? How to move foreign people through folk memories and local emotions, so that local features can realize the cross culture communication on the basis of inheritance? These are new problems which should be answered by Shanghai paper cutting inheritors.

\section{References}

[1] O.F. Li, Urban culture and modernity, in: O.F. Li, Unfinished Modernity, Peking University Press, Beijing, 2005.

[2] Mumford, J.L. Song (Trans), Urban Culture, China Architecture \& Building Press, Beijing, 2008.

[3] Z.M. Chen, The history of Shanghai and dialect formation, November 26, 2015

[4] Spengler, Y. Jiang (Trans), The Decline of the West, Hunan Literature and Art Publishing House, Changsha, 2011.

[5] [11] Bergere, J. Wang, N.G. Zhao (Trans),. History of Shanghai: the Road Toward Modernization, Shanghai Academy of Social Sciences Press, Shanghai, 2014.

[6] X. Sun, Shanghai culture: the forerunner of modern Chinese urban culture, J. Jiangxi Social Sciences. 10 (2010).

[7] J.H. Yu, History of Chinese Painting, The Commercial Press, Shanghai, 1937.

[8] X. Lu, "Beijing school" and "Shanghai school", in: Edition of Lu Xun's Essays, Lijiang Publishing Limited, Guilin, 2000.

[9] Y. Wang, Interpretation of Mr. Shikumen, J. Shanghai Economy. 4 (2013).

[10] H. Bausinger, X.H. Lu (Trans), Folk Culture in the Technological World, Guangxi Normal University Press, Guilin, 2014.

[12] X.Y. Peng, Prodigal Aesthetics and Cross-Cultural Modernity, Linking Publishing Co. Ltd, Taipei, 2012.

[13] Women's Pictorial, the seventeenth issue of April, 1934, pp.10-12.

[14] Y.L. Lu, The art life of Lin Tao, a Flower Nurse, Fujian Normal University, 2007.

[15] C.X. Wang, An overview of Manchu folk paper-cut in Changbai Mountain, J. Art, 04 (2003).

[16] Y.W. Zhang, Yesterday's lecture: worldly affairs of two places, 2015-9-13. 